\title{
Evaluation of the Effects of Bariatric Surgery in Terms of Weight Loss and Diabetes Remission in the Indian Population
}

\author{
Manish Khaitan Riddhish Gadani Koshish Nandan Pokharel \\ Bariatric and Metabolic Surgery, KD Hospital, Ahmedabad, India
}

\section{Keywords}

Excess weight loss - Laparoscopic sleeve gastrectomy · Mini-gastric bypass - Roux-en-Y gastric bypass - Type 2 diabetes mellitus

\begin{abstract}
Objectives: The growing prevalence of obesity rates worldwide is associated with an upsurge in its comorbidities, particularly type 2 diabetes mellitus (T2DM). Bariatric surgery is a proven treatment modality for producing sustained weight loss and resolution of associated T2DM providing marked improvement in quality of life with rapid recovery. This study aims to investigate the effects of laparoscopic sleeve gastrectomy (LSG), Roux-en-Y gastric bypass (RYGB), and minigastric bypass (MGB) on obese patients suffering from T2DM in the Indian population and their long-term association with regard to diabetes remission, resolution of comorbidities, and percentage EWL. Methods: Retrospective data of obese patients with T2DM (preoperative BMI $45.37 \pm 8.1$ ) who underwent bariatric surgery (RYGB, LSG, and MGB) were analyzed in this study over a period of 9 years. The mean follow-up period was 2.2 years. Following surgery, the clinical outcome on BMI, resolution of percentage weight loss, and T2DM were studied. The predictive factors of diabetic remission after surgery were determined. Student's $t$ test
\end{abstract}

karger@karger.com www.karger.com/dde

Karger $\stackrel{\text { ' }}{5}$
(C) 2021 The Author(s)

Published by S. Karger AG, Basel

This is an Open Access article licensed under the Creative Commons Attribution-NonCommercial-4.0 International License (CC BY-NC) (http://www.karger.com/Services/OpenAccessLicense), applicable to the online version of the article only. Usage and distribution for commercial purposes requires written permission. and ANOVA and McNemar's test were applied. Results: Out of a total of 274 patients, complete remission of T2DM was achieved in $52.9 \%(n=145)$ with mean fasting blood glucose and glycated hemoglobin values being $6.1 \pm 0.769(p=0.00)$ at 1 year after surgery. The independent predictive factors of remission were age, gender, $\mathrm{BMI}$, preoperative comorbidities, and \% EWL. Gender had no correlation with the chance of achieving disease remission. Conclusion: Based on our results, bariatric surgery proves to be a successful treatment option resulting in sustained weight loss in obese patients suffering from T2DM. It is found to be beneficial for the longterm resolution of T2DM and improving comorbidities such as hypertension and dyslipidemia. The outcome of the different surgical methods is found to be similar for all patients irrespective of the independent predictors of complete remission.

(c) 2021 The Author(s).

Published by S. Karger AG, Basel

\section{Introduction}

The upsurge in the prevalence of obesity is a reason behind the development or worsening of several complications. Type 2 diabetes mellitus (T2DM) is one of the major conditions affected by obesity $[1,2]$. It is affecting $>171$ million people globally while yearly around 3 mil- 
lion patients are succumbing to it. Currently, one-fifth of the world's population is overweight [1]. Bariatric surgery has demonstrated to be a viable therapeutic option in patients suffering from severe obesity. It is advocated in patients with BMI $>40 \mathrm{~kg} / \mathrm{m}^{2}$ or $35 \mathrm{~kg} / \mathrm{m}^{2}$ or above accompanied with at least 2 comorbidities including T2DM and different components of metabolic syndrome [3]. Weight loss induced via bariatric surgery is associated with reducing cardiovascular risk factors significantly [4].

There is mounting evidence that established the superiority of bariatric surgery over conventional medical treatment for improving outcomes related to T2DM [5]. Data from observational studies suggest that bariatric surgery has caused around $45-95 \%$ rate of diabetes remission. The rate of diabetes remission depends upon the procedure used in bariatric surgery [6]. A meta-analysis comprising 3,188 patients with T2DM who had undergone bariatric surgery demonstrated that $78 \%$ of patients reported resolution in T2DM while $87 \%$ of patients showed resolution or improvement [7]. An improvement or remission of diabetes is evident after bariatric surgery in obese patients with type 2 diabetes, and also there is a significant reduction in the mortality associated with diabetes [8]. Diabetes improvement was seen due to weight loss associated with bariatric surgery [9]. On the contrary, few studies reported the resolution of diabetes before achieving significant weight loss [10].

Several restrictive, malabsorptive, or combined bariatric procedures are currently available as a promising treatment for T2DM [11]. The Roux-en-Y gastric bypass (RYGB) reported a significant improvement or total resolution in patients with T2DM. The RYGB was able to attain better outcomes in terms of weight loss and T2DM resolution and long-term maintenance of these results than other restrictive procedures [12]. The RYGB is superior owing to potential mechanisms which alter gut hormones, ghrelin, and GLP-1 [13]. On the contrary, recent evidence recommends laparoscopic sleeve gastrectomy (LSG) as an absolute treatment for morbid obesity; the excess weight loss (EWL) was in the range of 50 83.3\% [14]. However, the contention is to demonstrate the long-term efficacy of different bariatric surgical procedures in a cohort of Indian patients at both 1 year and over a mean last follow-up of 2.2 years. The objective of this study was to retrospectively evaluate the effects of LSG, mini-gastric bypass (MGB), and RYGB on obese patients with T2DM and their long-term association with regard to diabetes remission, resolution of comorbidities, and percentage EWL.

\section{Materials and Methods}

\section{Study Design and Participants}

This is a retrospective observational study carried out with the objective of assessing the effect of bariatric surgery in terms of weight loss and on the evolution of metabolic parameters (T2DM, dyslipidemia, hypertension, and others). The study group included 274 obese patients who underwent RYGB, MGB, or LSG - between 2010 and 2018 in our center. The decision of which procedure to pursue was made between the surgeon and the patient based on needs and expectations. Data were collected from preoperative visits as well as postoperative visits each year during the 9 -year period.

\section{Clinical Parameters Evaluated}

Preoperatively, all patients were evaluated for medical history, and patient demographics were recorded. A clinical examination was carried out, and information on associated risk factors and comorbidities such as arterial hypertension, dyslipidemia, and others was collected. The serum levels of glycosylated hemoglobin were measured. Afterward, surgical procedures such as LSG, MGB, and RYGB were used. After surgery, patients were evaluated in terms of postoperative clinical outcomes, including percent EWL (\% EWL), complications, and improvement or resolution of preoperative comorbidities (T2DM, hypertension, obstructive sleep apnea, and hyperlipidemia) over a mean period of 2.2 years. A patient is regarded to be in diabetes remission if they meet no criteria of ADA guidelines 2019, that is, $\mathrm{HbA1c} \geq 6.5 \%$ and under the absence of antidiabetic medication and treatment during the defined observation period.

\section{Statistical Analysis}

The qualitative data were presented as number and percentages, while quantitative data were presented as mean \pm standard deviation and ranges. Continuous variables were evaluated for normality using the Shapiro-Wilk test. The comparison of normally distributed variables was assessed by paired $t$ test and ANOVA. McNemar's test was carried out to find out the differences in a dichotomous dependent variable between 2 related groups. Multivariate logistic regression analyses were conducted to evaluate the related risk factors like age, gender, BMI, preoperative comorbidities, surgical methods, and \% EWL. All the " $p$ " values $<0.05$ were deliberated as statistically significant. IBM SPSS statistics software version 20 was used for performing statistical analyses.

\section{Results}

\section{Participant Characteristics}

In all, 274 obese patients with T2DM underwent bariatric surgery between 2010 and 2018. Among the patients included in the study, $16.1 \%$ submitted to LSG, $3.6 \%$ to MGB, and $80.3 \%$ to RYGB. There were $168 \mathrm{fe}$ males $(61.3 \%)$ and 106 males $(38.7 \%)$ with a mean \pm SD age of $44.75( \pm 11.8)$ (range $20-75)$ years. The mean \pm SD weight of patients was $118.93 \pm 24.7$ with a range of $68-250 \mathrm{~kg}$. For height, it was $161.98 \pm 9.9$ with a range of 
Table 1. Patients' baseline characteristics at the time of surgery

\begin{tabular}{llll}
\hline Descriptive statistics & Sample & Mean \pm SD or $n$ (\%) & Range \\
\hline Age, years & 274 & $44.75 \pm 11.8$ & $20-75$ \\
$\begin{array}{l}\text { Gender, } n \text { (\%) } \\
\quad \text { Male }\end{array}$ & 274 & & \\
$\quad$ Female & & $106(38.7)$ & \\
Preop weight, kg & 274 & $168(61.3)$ & $68-250$ \\
Height, cm & 274 & $118.93 \pm 24.7$ & $136-189$ \\
BMI, kg/m ${ }^{2}$ & 274 & $45.37 \pm 8.1$ & $29.4-87.5$ \\
Preop HbA1c & 274 & $8.2 \pm 1.5$ & $6-13$ \\
Time of last follow-up, years & 274 & $2.2 \pm 1.4$ & $1-6.8$ \\
Median time of follow-up, years & 274 & 1.7 & $1.1-2.6^{* *}$ \\
Preoperative comorbidity, $n$ (\%) & 274 & & \\
$\quad$ Hypertension & & $136(49.6)$ & \\
Dyslipidemia & & $54(19.7)$ & \\
OSA & & $14(5.1)$ & \\
Others & & $60(21.9)$ & \\
Surgical method, $n$ (\%) & & & \\
LSG & 274 & $44(16.1)$ & \\
MGB & & $10(3.6)$ & \\
RYGB & & $220(80.3)$ & \\
\hline
\end{tabular}

OSA, obstructive sleep apnea; LSG, laparoscopic sleeve gastrectomy; RYGB, Roux-en-Y gastric bypass; MGB, mini-gastric bypass; IQR, interquartile range. ** IQR (1st quartile-3rd quartile). \# Others include epilepsy, GERD, kidney/liver diseases, psychiatric, thyroid issues, and pains.
$136-189 \mathrm{~cm}$. All patients had the mean initial BMI of $45.37 \pm 8.1$ with a range $\left(29.4-87.5 \mathrm{~kg} / \mathrm{m}^{2}\right)$. The mean \pm SD HbAlc before operation was $8.2 \pm 1.5$ with a range of $6-13 \%$. With regard to preoperative comorbidities, $49.6 \%$ of the patients had hypertension, $19.7 \%$ had dyslipidemia, 5.1\% had obstructive sleep apnea, and 21.9\% had other comorbidities (Table 1). The mean period of follow-up was $2.2 \pm 1.4$ (range 1-6.8) years, and the median length of follow-up was 1.7 years (IQR 1.1-2.6 years).

\section{Postoperative Results}

The changes in body weight, resolution of comorbidities, and $\mathrm{HbA1c}$ values following LSG, MGB, and RYGB are reported in Table 2. One year after the surgery, patients achieved a mean weight of $83.5 \pm 22.6 \mathrm{~kg}$ from $118.93 \pm 24.7 \mathrm{~kg}$ of initial weight reported at baseline. A significant change in the patient's weight was obtained at the last follow-up, reaching $80.8 \pm 21 \mathrm{~kg}$. The mean $\pm \mathrm{SD}$ weight loss was found to be $64.4 \pm 46.4$ and $73.4 \pm 42.6$ after 1 year and at last follow-up, respectively. The longterm follow-up made us understand the durability of the improvement or resolution of obesity-associated comorbidities. The improvement in all comorbidities was striking, that is, $61 \%$ of patients had remission of hyperten sion, $31.5 \%$ had remission of dyslipidemia, and $66.7 \%$ had remission of other comorbidities at the end of 1 year. A remarkable improvement has been found at the end of the last follow-up where hypertension was resolved in $97.1 \%$ of patients, dyslipidemia in $79.6 \%$, and other comorbidities in $18.3 \%$ of patients. For all the patients with obesity suffering from diabetes, the serum $\mathrm{HbAlc}$ level was reduced significantly from $8.2 \pm 1.5$ to $6.1 \pm 0.7691$ year following surgery. However, different surgical procedures did not differ significantly in terms of decrease in HbAlc levels $(p=0.792)$.

The diabetes improvement was significant $(p=0.00)$ after bariatric surgery irrespective of the overall surgical approach. In total, 145 (52.9\%) patients achieved diabetes remission at 1 year postoperatively $(p=0.00)$. Thirty-four patients were lost to follow-up, and 145 patients (60.4\%) out of 240 achieved remission at the end of the last followup. However, it is intriguing to see that 13 patients (9\%) had diabetes recurrence after initial diabetes remission (Table 3).

\section{Multivariable Analysis}

Logistic regression was carried out to establish the effects of age, gender, BMI, preoperative comorbidities, surgical methods, and \% EWL on remission of diabetes 
Table 2. Excess weight loss, resolution of comorbidities, and $\mathrm{HbA} 1 \mathrm{c}$ status from baseline
Table 3. Status of remission of diabetes mellitus

\begin{tabular}{|c|c|c|}
\hline Descriptive statistics & $\begin{array}{l}\text { Mean } \pm \text { SD or } \\
n(\%)\end{array}$ & $\begin{array}{l}\text { Remission from } \\
\text { baseline }\end{array}$ \\
\hline $\begin{array}{l}\text { HbA1c at } 1 \text { year* }(n=274) \\
\text { LSG } \\
\text { MGB } \\
\text { RYGB }\end{array}$ & $\begin{array}{l}6.1 \pm 0.769 \\
p=0.792^{* *}\end{array}$ & $4.9-8.5^{\#}$ \\
\hline \multicolumn{3}{|c|}{ Comorbidity status at 1 year, $n(\%)$} \\
\hline Hypertension & $53(19.3)$ & 61 \\
\hline Dyslipidemia & 37 (13.5) & 31.5 \\
\hline Others & $20(7.2)$ & 66.7 \\
\hline \multicolumn{3}{|c|}{ Comorbidity status at the last follow-up, $n$ (\%) } \\
\hline Hypertension & $4(1.5)$ & 97.1 \\
\hline Dyslipidemia & $11(4)$ & 79.6 \\
\hline Others & $49(17.8)$ & 18.3 \\
\hline \multicolumn{3}{|l|}{ Weight, kg } \\
\hline At 1 year & $83.5 \pm 22.6$ & $49-185$ \\
\hline At last follow-up & $80.8 \pm 21$ & $42-186$ \\
\hline \multicolumn{3}{|c|}{$\%$ excess weight loss at $\mathrm{BMI}=25$} \\
\hline At 1 year & $64.4 \pm 46.4$ & -213.9 to $161 \%$ \\
\hline At last follow-up & $73.4 \pm 42.6$ & -214 to $290 \%$ \\
\hline
\end{tabular}

LSG, laparoscopic sleeve gastrectomy; RYGB, Roux-en-Y gastric bypass; MGB, mini-gastric bypass. ${ }^{*}$ Used paired $t$ test to compare from baseline; significant decrease with $p$ value $<0.001$. "Range. ** $p$ value from the ANOVA test.

\begin{tabular}{lllll}
\hline Time & Diabetic & Remission, $\%$ & Recurrence, \% & $p$ value* \\
\hline $\begin{array}{l}\text { Preoperative (A), } N=274 \\
\text { Postoperative 1 year (B), } n(\%)\end{array}$ & $129(47.1)$ & $145(52.9)$ & & 0.00 (B vs. A) \\
Last follow-up (C) ${ }^{*}, n(\%)$ & $95(39.6)$ & $145(60.4)$ & $13(9)$ & 0.00 (C vs. A) \\
\hline & ${ }^{*}$ McNemar's test, significant if $p$ value <0.05; otherwise not significant. \# Thirty-four lost \\
to follow-up.
\end{tabular}

after bariatric surgery. The model explained 23.8\% (Nagelkerke $R^{2}$ ) of the variance in the remission and correctly classified $91.0 \%$ of cases. Patients with age $\geq 50$ years are $16 \%$ less likely to reach complete remission of T2DM compared with patients with age $<50$ years (OR $=0.84,95 \%$ CI: $0.5-1.42, p=0.51)$. Patients with no preoperative dyslipidemia were $57 \%(\mathrm{OR}=0.43,95 \%$ CI: $0.22-0.84)$ less likely to exhibit diabetes remission as compared to those who had preoperative dyslipidemia $(p=0.01)$. Increasing $\%$ EWL was positively associated with diabetes remission. Of the selected preoperative factors, irrespective of gender, BMI, preoperative hypertension, and other comorbidities, surgical methods did not remain statistically significant with diabetes remission in the multivariable analyses (Table 4).

\section{Discussion/Conclusion}

Bariatric surgery is able to reduce weight, decrease morbidity and mortality, and improve quality of life. The outcome measures of bariatric surgery have been well documented in the literature [15-18]. This study reinforces the observation that bariatric surgery (LSG, MGB, and RYGB) is an effective procedure causing a substantial weight loss during the first year after surgery and favorable effect on diabetes remission. In our study, weight was reduced by $35.43 \pm 2.1$ and $38.13 \pm 3.7 \mathrm{~kg}$ in patients at 1 year and at last follow-up, respectively. With regard to the resolution of T2DM, 52.9\% of diabetes remission occurred at 1-year follow-up. This is in line with previous findings where 1-year remission rates varied between $50 \%$ and $80 \%$ [19-23]. 
Table 4. ORs for reaching diabetes remission at 1 year and last follow-up after surgery

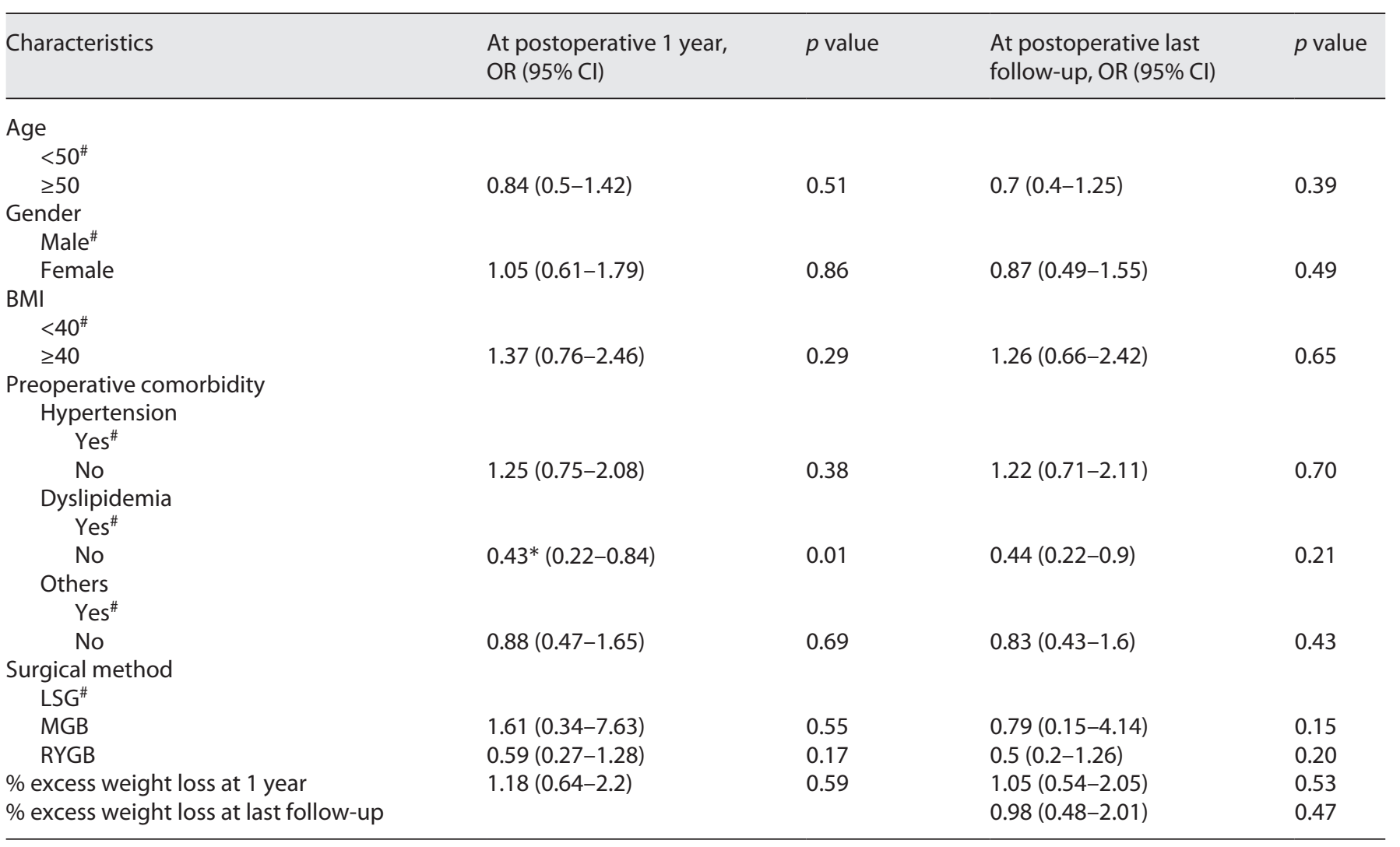

OR, odds ratios; $\mathrm{Cl}$, confidence interval; \#, reference; LSG, laparoscopic sleeve gastrectomy; RYGB, Roux-en-Y gastric bypass; MGB, minigastric bypass. Significant if $p$ value $<0.05$; otherwise not significant.

A meta-analysis including 15 studies $(n=1,753)$ reported the predictive factors older age, long duration of diabetes, current insulin use, and poor glycemic control for poor diabetes remission after bariatric surgery [24]. The predictive factors we found in our analysis are consistent with other studies which include age, gender, BMI, EWL, preoperative comorbidity, and different surgical methods used [25-29].

Age was negatively correlated with the possibility of diabetes remission [30]. In our study, we found that patients $>50$ years of age are $16 \%$ less prone to reach remission of T2DM compared with patients $<50$ years old. It has been reported that aging is associated with increased fat mass, and younger patients are inclined to lose excess BMI compared to patients $>45$ years of age. As a result, the metabolic capacity was hampered in older patients and an elongated duration of comorbidities, a factor which could have guided the reduced chance of achieving complete remission [31, 32].

Bariatric Surgery for Weight Loss and Diabetes Remission
Furthermore, female T2DM patients showed a better remission rate at 1 year $(p=0.86)$ and at the last followup $(p=0.49)$ and correlated well compared to the male patients. According to a recent study [33], a decrease in $\%$ EWL was found more predominant in women than in men during the initial 3 years or perhaps due to the fact that the female sample size in our study was greater than the male one, which may have influenced the results.

Markers of preoperative comorbidities in our study cohort exhibited a negative effect on diabetes remission. Our findings suggest that patients with no preoperative dyslipidemia were $57 \%$ less likely to exhibit diabetes remission as compared to those who had preoperative dyslipidemia $(p=0.01)$ at 1 year.

In this study, a positive association between increasing $\% \mathrm{EWL}$ and the chance of diabetes remission after bariatric surgery was seen. EWL was in direct association with diabetes remission $(p=0.59)$ at 1 year. The association between increasing percentage weight loss and improved

Dubai Diabetes Endocrinol J 2021;27:119-125 
remission rates was reported by several randomized controlled trials and cohort studies which collectively supported the perception that greater weight loss brings higher possibilities of T2DM remission [34-36].

Several studies comparing RYGB and LSG have shown that RYGB improves diabetes remission rate compared with LSG [37-39]. On the contrary, some studies indicated similar results between both techniques [40]. In our study, irrespective of gender, BMI, and preoperative comorbidities, no statistically significant differences were found between different surgical methods with regard to diabetes remission.

However, this study had some limitations. First, it was a single-center retrospective study. Second, there is an inequality of the 3 groups - RYGB, MGB, and LSG, that is, the number of patients who had undergone RYGB is higher compared to the patients who had undergone MGB. Also, there was no mention of antidiabetic medications before and after surgery.

The important asset of this study is that patients were successively selected at 1 center and had undergone 3 different surgical techniques, that is, LSG, RYGB, and MGB. Furthermore, to our knowledge, our study had a relatively larger sample size compared with other series available in the Indian population which can balance the other mentioned limitations.

To conclude, bariatric surgery is an evidence-based approach supporting significant and sustainable weight loss in obese people. The presence of strong evidence suggests that T2DM is either improved or resolved after bariatric surgery that was durable in the long term. Our study provides further evidence that diabetes remission occurred in $68.1 \%$ of patients by 1 year after bariatric surgery indicating that bariatric surgery is a safe, efficient procedure to improve type 2 diabetes and associated comorbidities.

\section{Statement of Ethics}

The study was approved by the Institutional Ethics Committee of KD Hospital (Ref No. 01/kd/IEC/2020; Dated 06 August 2020) and conducted in accordance with the ethical standards of the ICH-GCP and Declaration of Helsinki guidelines. Written consent was obtained from the study participants after explaining the details of the surgery, its pros and cons, and all intraoperative, early, and late postoperative complications that could occur. Furthermore, all participants were informed of the research and that the data would be used for research purposes, giving patients the right to decline participation.

\section{Conflict of Interest Statement}

The authors have no conflicts of interest to declare.

\section{Funding Sources}

No funding sources were reported by the authors.

\section{Author Contributions}

All authors named in this manuscript contributed to the conception, conduct, and data analysis of the study and were involved in drafting, further development, and revision of the manuscript and approval of its final version.

\section{Data Availability Statement}

The data that support the findings of this study are not publicly available due to the confidentiality of the participants, for example, they contain information that could compromise the privacy of research participants, but are available from the corresponding author on reasonable request.

\section{References}

1 Kelly T, Yang W, Chen CS, Reynolds K, He J. Global burden of obesity in 2005 and projections to 2030. Int J Obes. 2008 Sep;32(9): 1431-7.

2 Park HJ, Hong SS, Hwang J, Hur KY. Mini-gastric bypass to control morbid obesity and diabetes mellitus: what radiologists need to know. Korean J Radiol. 2015 Mar; 16(2):325-33.

3 Dixon JB, Zimmet P, Alberti KG, Rubino F; International Diabetes Federation Taskforce on Epidemiology and Prevention. Bariatric surgery: an IDF statement for obese type 2 diabetes. Surg Obes Relat Dis. 2011 Jul 1;7(4): 433-47.
4 Benaiges D, Goday A, Ramon JM, Hernandez E, Pera M, Cano JF, et al. Laparoscopic sleeve gastrectomy and laparoscopic gastric bypass are equally effective for reduction of cardiovascular risk in severely obese patients at one year of follow-up. Surg Obes Relat Dis. 2011 Sep 1;7(5):575-80.

5 Dixon JB, Le Roux CW, Rubino F, Zimmet P. Bariatric surgery for type 2 diabetes. Lancet. 2012 Jun 16;379(9833):2300-11.

6 Buchwald H, Avidor Y, Braunwald E, Jensen MD, Pories W, Fahrbach K, et al. Bariatric surgery: a systematic review and meta-analysis. JAMA. 2004 Oct 13;292(14):1724-37.
7 Buchwald H, Estok R, Fahrbach K, Banel D, Jensen MD, Pories WJ, et al. Weight and type 2 diabetes after bariatric surgery: systematic review and meta-analysis. Am J Med. 2009 Mar 1;122(3):248-56.e5.

8 Gill RS, Birch DW, Shi X, Sharma AM, Karmali S. Sleeve gastrectomy and type 2 diabetes mellitus: a systematic review. Surg Obes Relat Dis. 2010 Nov 1;6(6):707-13.

9 Kadera BE, Lum K, Grant J, Pryor AD, Portenier DD, DeMaria EJ. Remission of type 2 diabetes after Roux-en-Y gastric bypass is associated with greater weight loss. Surg Obes Relat Dis. 2009 May 1;5(3):305-9. 
10 Garrido-Sanchez L, Murri M, Rivas-Becerra J, Ocaña-Wilhelmi L, Cohen RV, Garcia-Fuentes $\mathrm{E}$, et al. Bypass of the duodenum improves insulin resistance much more rapidly than sleeve gastrectomy. Surg Obes Relat Dis. 2012 Mar 1;8(2):145-50.

11 Vetter ML, Ritter S, Wadden TA, Sarwer DB. Comparison of bariatric surgical procedures for diabetes remission: efficacy and mechanisms. Diabetes Spectr. 2012 Nov 1;25(4): 200-10.

12 Obeid A, Long J, Kakade M, Clements RH, Stahl R, Grams J. Laparoscopic Roux-en-Y gastric bypass: long term clinical outcomes. Surg Endosc. 2012 Dec;26(12):3515-20.

13 Cummings DE, Overduin J, Shannon $\mathrm{MH}$, Foster-Schubert KE; 2004 ABS Consensus Conference. Hormonal mechanisms of weight loss and diabetes resolution after bariatric surgery. Surg Obes Relat Dis. 2005 May 1;1(3):358-68.

14 Moon Han S, Kim WW, Oh JH. Results of laparoscopic sleeve gastrectomy (LSG) at 1 year in morbidly obese Korean patients. Obes Surg. 2005 Nov; 15(10):1469-75.

15 Sjöström L, Peltonen M, Jacobson P, Sjöström $\mathrm{CD}$, Karason K, Wedel H, et al. Bariatric surgery and long-term cardiovascular events. JAMA. 2012 Jan 4;307(1):56-65.

16 Scott WR, Batterham RL. Roux-en-Y gastric bypass and laparoscopic sleeve gastrectomy: understanding weight loss and improvements in type 2 diabetes after bariatric surgery. Am J Physiol Regul Integr Comp Physiol. 2011 Jul; 301(1):R15-27.

17 Sjöström L. Bariatric surgery and reduction in morbidity and mortality: experiences from the SOS study. Int J Obes. 2008 Dec;32 Suppl 7(7):S93-7.

18 Pournaras DJ, Aasheim ET, Søvik TT, Andrews R, Mahon D, Welbourn R, et al. Effect of the definition of type II diabetes remission in the evaluation of bariatric surgery for metabolic disorders. Br J Surg. 2012 Jan;99(1): 100-3.

19 Debédat J, Sokolovska N, Coupaye M, Panunzi S, Chakaroun R, Genser L, et al. Longterm relapse of type 2 diabetes after Roux-en$Y$ gastric bypass: prediction and clinical relevance. Diabetes Care. 2018 Oct 1;41(10): 2086-95.

20 Kadera BE, Lum K, Grant J, Pryor AD, Portenier DD, DeMaria EJ. Remission of type 2 diabetes after Roux-en- $Y$ gastric bypass is associated with greater weight loss. Surg Obes Relat Dis. 2009 May 1;5(3):305-9.
21 Hariri K, Guevara D, Jayaram A, Kini SU, Herron DM, Fernandez-Ranvier G. Preoperative insulin therapy as a marker for type 2 diabetes remission in obese patients after bariatric surgery. Surg Obes Relat Dis. 2018 Mar 1;14(3):332-7.

22 Ramos-Levi A, Sanchez-Pernaute A, Matia P, Cabrerizo L, Barabash A, Hernandez C, et al. Diagnosis of diabetes remission after bariatic surgery may be jeopardized by remission criteria and previous hypoglycemic treatment. Obes Surg. 2013 Oct;23(10):1520-6.

23 Ramos-Levi AM, Cabrerizo L, Matía P, Sánchez-Pernaute A, Torres AJ, Rubio MA. Which criteria should be used to define type 2 diabetes remission after bariatric surgery? BMC Surg. 2013 Dec;13(1):8-3.

24 Wang GF, Yan YX, Xu N, Yin D, Hui Y, Zhang JP, et al. Predictive factors of type $2 \mathrm{di}$ abetes mellitus remission following bariatric surgery: a meta-analysis. Obes Surg. 2015 Feb; 25(2):199-208.

25 Panunzi S, De Gaetano A, Carnicelli A, Mingrone G. Predictors of remission of diabetes mellitus in severely obese individuals undergoing bariatric surgery: do BMI or procedure choice matter? A meta-analysis. Ann Surg. 2015 Mar 1;261(3):459-67.

26 Still CD, Wood GC, Benotti P, Petrick AT, Gabrielsen J, Strodel WE, et al. Preoperative prediction of type 2 diabetes remission after Roux-en-Y gastric bypass surgery: a retrospective cohort study. Lancet Diabetes Endocrinol. 2014 Jan 1;2(1):38-45.

27 Blackstone R, Bunt JC, Cortés MC, Sugerman HJ. Type 2 diabetes after gastric bypass: remission in five models using HbAlc, fasting blood glucose, and medication status. Surg Obes Relat Dis. 2012 Sep 1;8(5):548-55.

28 Dixon JB, Chuang LM, Chong K, Chen SC, Lambert GW, Straznicky NE, et al. Predicting the glycemic response to gastric bypass surgery in patients with type 2 diabetes. Diabetes Care. 2013 Jan 1;36(1):20-6

29 Robert M, Ferrand-Gaillard C, Disse E, Espalieu P, Simon C, Laville M, et al. Predictive factors of type 2 diabetes remission 1 year after bariatric surgery: impact of surgical techniques. Obes Surg. 2013 Jun;23(6):770-5.

30 Aung L, Lee WJ, Chen SC, Ser KH, Wu CC, Chong $\mathrm{K}$, et al. Bariatric surgery for patients with early-onset vs late-onset type 2 diabetes. JAMA Surg. 2016 Sep 1;151(9):798-805.

31 Villareal DT, Apovian CM, Kushner RF, Klein S. Obesity in older adults: technical review and position statement of the American Society for Nutrition and NAASO, The Obesity Society. Am J Clin Nutr. 2005 Nov 1; 82(5):923-34
32 Frattini F, Rausei S, Ferrari C, Rovera F, Boni L, Dionigi G. Need of standardization in bariatric surgery: is it time to think about? Comment on Contreras JE, Santander C, Court I, Bravo J. Correlation between age and weight loss after bariatric surgery. Obesity surgery 2013; 23 (8): 1286-9. Obes Surg. 2014 Nov; 24(11):1994.

33 Guerreiro V, Neves JS, Salazar D, Ferreira MJ, Oliveira SC, Souteiro P, et al. Long-term weight loss and metabolic syndrome remission after bariatric surgery: the effect of sex, age, metabolic parameters and surgical technique: a 4-year follow-up study. Obes Facts. 2019;12(6):639-52.

34 Berggren J, Lindqvist A, Hedenbro J, Groop L, Wierup N. Roux-en-Y gastric bypass versus calorie restriction: support for surgery per se as the direct contributor to altered responses of insulin and incretins to a mixed meal. Surg Obes Relat Dis. 2017 Feb 1;13(2):234-42.

35 Bojsen-Møller KN, Dirksen C, Jørgensen NB, Jacobsen SH, Hansen DL, Worm D, et al. Increased hepatic insulin clearance after Rouxen-Y gastric bypass. J Clin Endocrinol Metab. 2013 Jun 1;98(6):E1066-71.

36 Pessoa BM, Browning MG, Mazzini GS, Wolfe L, Kaplan A, Khoraki J, et al. Factors mediating type 2 diabetes remission and relapse after gastric bypass surgery. J Am Coll Surg. 2020 Jan 1;230(1):7-16.

37 Pournaras DJ, Osborne A, Hawkins SC, Vincent RP, Mahon D, Ewings P, et al. Remission of type 2 diabetes after gastric bypass and banding: mechanisms and 2 year outcomes. Ann Surg. 2010 Dec 1;252(6):966-71.

38 Menguer RK, Weston AC, Schmid H. Evaluation of metabolic syndrome in morbidly obese patients submitted to laparoscopic bariatric surgery: comparison of the results between roux-En-Y gastric bypass and sleeve gastrectomy. Obes Surg. 2017 Jul;27(7):171923.

39 Souteiro P, Belo S, Neves JS, Magalhães D, Silva RB, Oliveira SC, et al. Preoperative beta cell function is predictive of diabetes remission after bariatric surgery. Obes Surg. 2017 Feb 1; 27(2):288-94.

40 Peterli R, Borbély Y, Kern B, Gass M, Peters $\mathrm{T}$, Thurnheer M, et al. Early results of the Swiss Multicentre Bypass or Sleeve Study (SM-BOSS): a prospective randomized trial comparing laparoscopic sleeve gastrectomy and Roux-en-Y gastric bypass. Ann Surg. 2013 Nov;258(5):690-4 